\section{Three Stories on Adam}

\author{
S. Joshua Swamidass (D) \\ https://doi.org/10.54739/3doe
}

$\mathrm{t}$ all begins with a deceptively simple question:

Do we descend from a single original couple?

It is a subtle question, with a great deal of complexity. The answers here are consequential. Here is where much conflict lies. In this workshop, we will look at how three different stories of Adam unfolded. There isn't no positive evidence for any of these stories, but there may be no evidence against them.

The first story is the most technical, and it is about sole-genetic progenitorship (discussion). If Adam and Eve were more ancient than 500-700 thousand years ago, they could have been our sole-genetic progenitors. This would mean all "humans" would descend directly from Adam and Eve, and their offspring never interbred with others.

The second story is the most recent, and it is about genetic-interbreeding progenitorship (discussion). If Adam and Eve were about 200 thousand years ago, it might be possible they were the genetic progenitors of Homo sapiens, as long as their offspring interbred with other hominids like Neanderthals. This finding is not settled yet, and will be looked at more closely with Reasons to Believe this Fall

The third story is the most surprising, and it is about sole-genealogical progenitorship (discussion). As recently as 6,000 years ago, Adam and Eve could have been created de novo, in the Middle East, ancestors of us all. Their offspring, however, would have interbred extensively with those outside the The Garden. This is The Genealogical Adam we have been putting forward for over a year now.

At the 2018 ASA meeting last week, I led a workshop on " Reworking the Science of Adam." To a standing room only crowd, I shared about three stories of Adam, and how they bring us to the grand questions of origins. Unfortunately, rules were changed at the last minute to forbid any recordings of the workshop. The primary goal of this event was to record and disseminate the contributions of the distinguished panelists. To keep the conversation going, I am summarizing the main points the workshop here. For more information, join the conversation with Greg Cootsona about the workshop on August 8-10th.

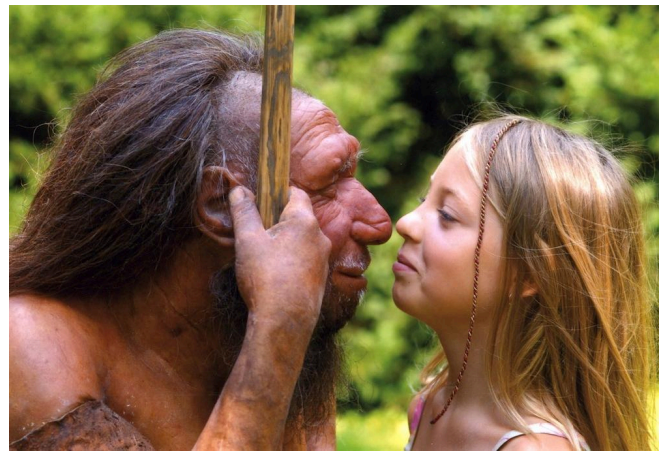

All these stories raise distinct theological questions. I'll enumerate them later. For now, I want to lay out the key scientific advances.

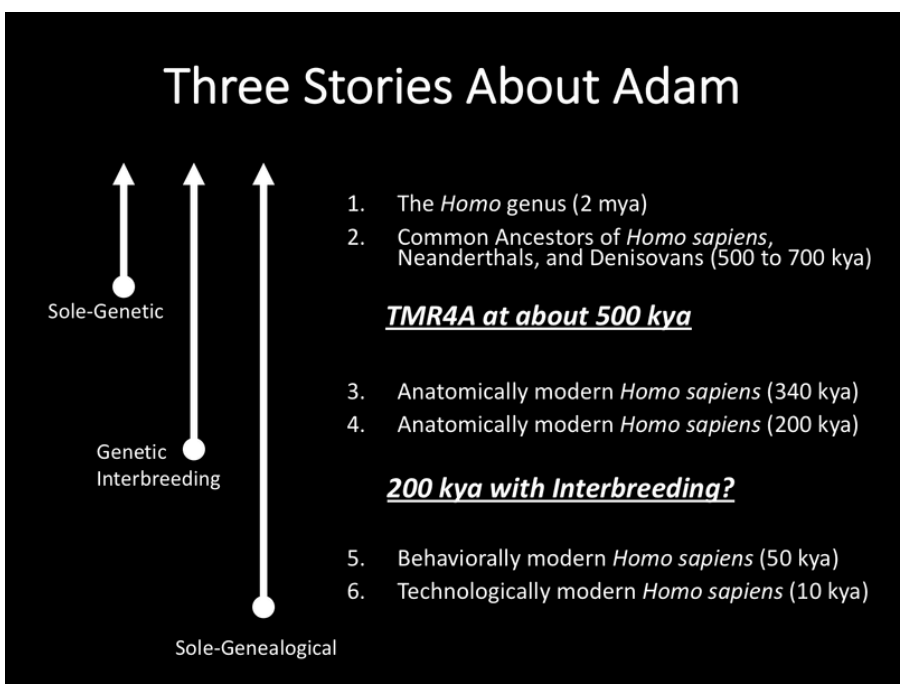

\section{Story One: Sole-Genetic Progenitorship}

This story unfolded in the comments of a blog, in conversation between Richard Buggs, Dennis Venema, and three other scientists. In early 2017, Dennis Venema and Scot McKnight published Adam and the Genome. New knowledge was uncovered and we owe it all to Richard Buggs.

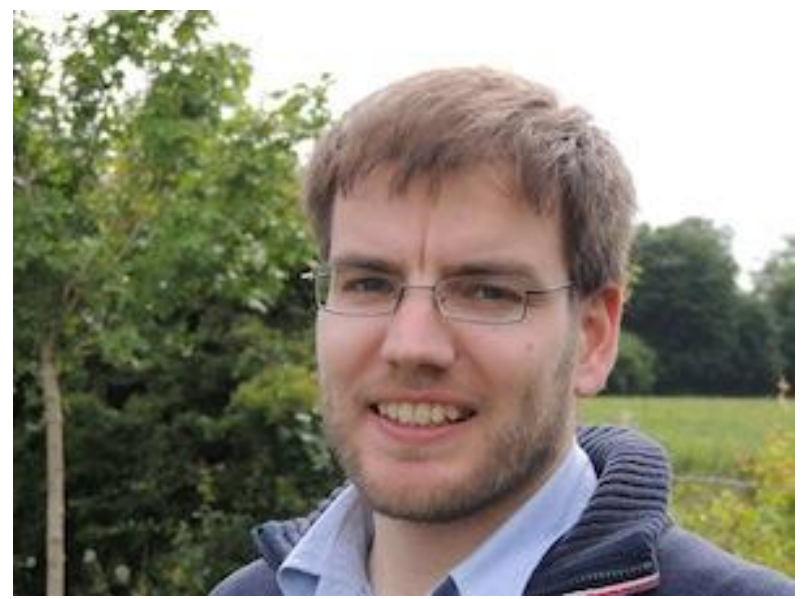




\section{Owing Richard Buggs}

Buggs is an untenured professor at a secular institution in England, with a wife and young child. He read Adam and the Genome, a recent book by Dennis Venema. This book claims that "humans" never went through bottleneck of a single couple, where some might look to find Adam and Eve. Buggs, however, was skeptical of the case offered for these claims. He approached Venema privately first, with an email, asking to clarify the science. No response. Then he sent a message by an intermediary. No response. Finally, he posted a public blog challenging the claims. This challenge was ignored for months.

I was in email communication with him at the time. The public challenge was a difficult step for Buggs; he was torn about if it was the right thing to do. It certainly was a risky thing to do. The origins debate is full of people arguing from safety, one way or another. Sometimes, in moments like these, more important things are taking place. We need to pause, step back, and listen. This was one of those moments.

Months later, Venema responded on a blog. A claim was made that the evidence against a bottleneck when back as far as 18 million years.

\section{In the Comments of a Blog}

What happened next was remarkable. Five scientists entered into prolonged dialogue about population genetics: Dennis Venema, Richard Buggs, of course, but also Ann Gauger (Discovery Institute), Stephen Schaffner (Broad Institute), and myself (WUSTL). In about 1.2 thousand posts, we hashed out what the evidence really showed. Our findings were surprising.

First, some of the arguments against a bottleneck were fallacious. This includes all the arguments in a key 2010 article, and most the arguments that are commonly put forward.

1. The argument from "Allelic Multiplicity." This was published several times since 2010, online and in print, but never peerreviewed. "In fact, to generate the number of alleles we see in the present day from a starting point of just two individuals, one would have to postulate mutation rates far in excess of what we observe for any animal." This is a fallacious argument that does not appear in the scientific literature.

2. The argument from "Population Size Estimates." This includes every publish estimate of population size (Ne), including LD, PSMC, MSMC, Alu, and any other method that estimates Ne. "To date, every genetic analysis estimating ancestral population sizes has agreed that we descend from a population of thousands, not a single ancestral couple." It had been missed that a brief bottleneck is consistent with a high $\mathrm{Ne}$, which denotes the average not the minimum population size over a long time period. This is a fallacious argument against a bottleneck.

Several lines of evidence were considered after this, including transspecies variation of HLA and allele frequency spectrum (AFS). None of the population genetics arguments from Dennis Venema's book held up. Only one line of evidence ultimately stood up to scrutiny, the evidence for interbreeding between Neanderthals and Homo sapiens. This evidence, however, is not merely population genetics, does not account for the genetic diversity of modern humans, and certainly does not stretch back 18 million years. Is this really the end of it all? That population genetics does not tell us about a bottleneck of two?

We needed a better way to look at the data. Richard Buggs brought the question. The two of us together designed an analysis, which we called Time to Most Recent Four Alleles (TMR4A). Then I ran the analysis across the genome. We found that this puts a limit of about 500 thousand years on a bottleneck. More ancient than this, there does not appear to be strong evidence against a bottleneck. That means, if "human" is either of these two definitions, perhaps Adam and Eve could be the sole-genetic progenitors of all of us: (1) The Homo genus (2 mya), or (2) Common Ancestors of Homo sapiens, Neanderthals, and Denisovans (500 to 700 kya).

This is a new finding, we only uncovered because Buggs asked the question at personal risk. We all owe him greatly.

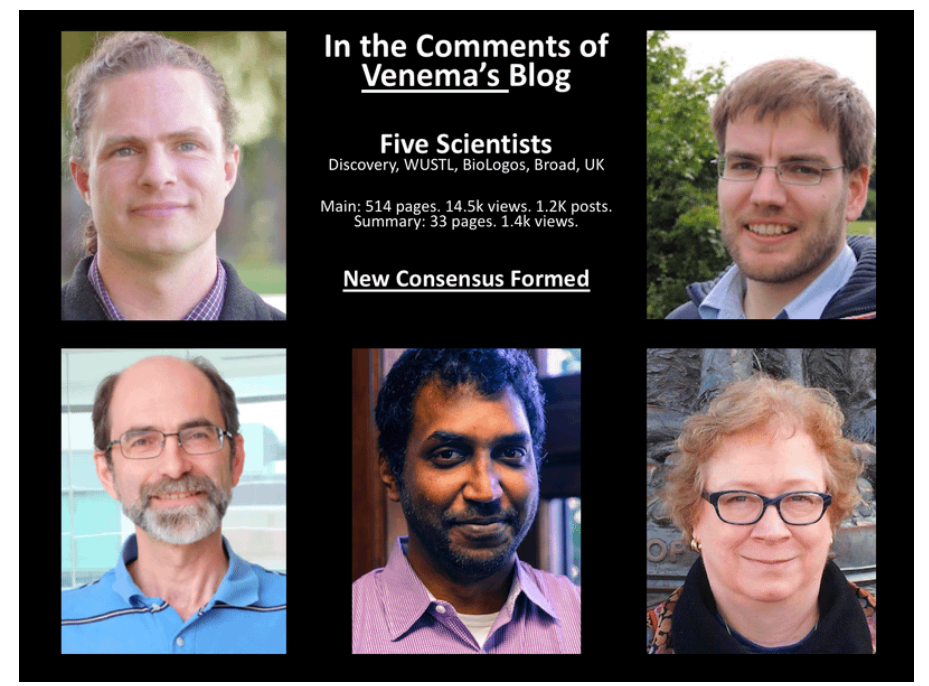

\section{Story Two: Genetic-Interbreeding Progenitorship}

It seemed that this was strong evidence against the Reasons to Believe model of human origins, which asserts that Homo sapiens arise with Adam and Eve as their sole progenitors. Dialogue with A.J. Roberts, however, clarified that their model was updated to include interbreeding with Neanderthals. That means it is no longer a solegenetic progenitor model. The good news is that this might be compatible with the evidence. This conversation will continue this Fall, in dialogue with Reasons to Believe. We hope to settle this question. Perhaps a Genetic-Interbreeding Progenitor model of Homo sapiens might be consistent with the evidence. This story is just beginning. I'm looking forward to see how it plays out. 


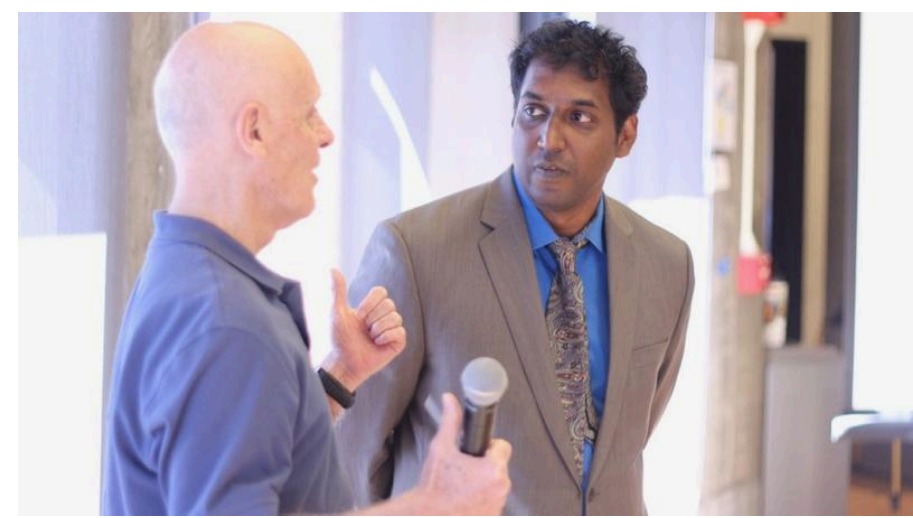

\section{Story Three: Sole-Genealogical Progenitorship}

This story begins back in April 2017, when I first brought forward The Genealogical Adam. Here, we start with two facts that were overlooked.

1. Genealogical Ancestry is not Genetic Ancestry.

2. Theology has legitimate autonomy to define "human" however it likes.

From here, we find out, it is possible that Adam and Eve were de novo (or not) created recently (6,000 years ago or more). Leaving the Garden, they could have become ancestors of us all, as their offspring interbred with those outside the Garden. This allows for several different hermeneutical, scientific, and theological integrations, including traditional de novo Adam (sole-progenitorship and monogenesis, unity of all mankind).

In this scenario, Adam and Eve could be de novo created as recent as just 6,000 years ago. One important model, put forward in the recent Dabar Conference, is to use three converging definitions of "human:"

1. The genealogical descendants of Adam and Eve (the "adams" of Genesis).

2. At least everyone to "the ends of the earth" by AD 1.

3. All those God-Imaged and Fallen in all history.

These three definitions come to refer to the same group of people if original sin is inherited by genealogical descent from Adam and Eve. In this way, they become our sole-genealogical ancestors, even though they are not our genetic ancestors. This theological model was worked out in detail at the Dabar Conference, and is currently being developed into a book.

If that is all confusing, do not be discouraged. Population genetics is deeply non-intuitive. This iconic figure might help make sense of it:

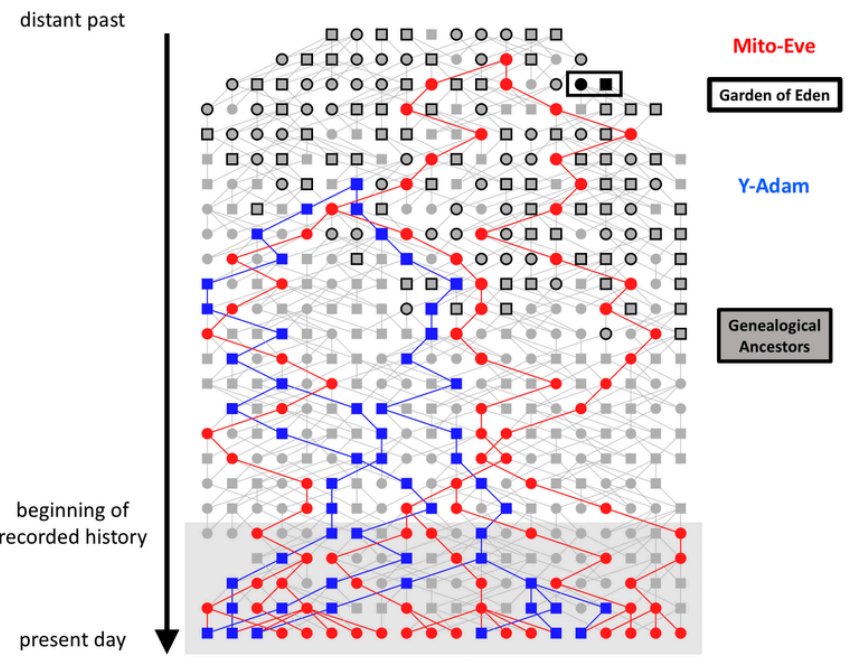

Genealogical ancestry is not genetic ancestry. Illustrating the story in the text, we show a cartooned pedigree, a genealogy, from past (top) to present (bottom). Squares and circles denote men and women, respectively, with lines indicating parentage. Red and blue individuals are those in the genetic lineages to a single ancestor, Mito-Eve and Y-Adam, respectively. In contrast, every individual with a black border is a common genealogical ancestor of all those in recorded history (grey box). The Scriptural Adam and Eve (the black box and square) are created from the dust and a rib less than 10,000 years ago, have no parents, are in the Garden of Eden (black box), and are genealogical ancestors of everyone in history. This story is entirely consistent with the genetic data.

\section{Does Anyone Care?}

This is a question that arises in the Church, and people care.

The Gospel Coalition and Tim Keller published a video on the essential doctrines of creation, which included the de novo creation of Adam. They were incorrectly told that this doctrine puts them in conflict with science. The Genealogical Adam, however, shows how their doctrine could be compatible with science. They care about this work.

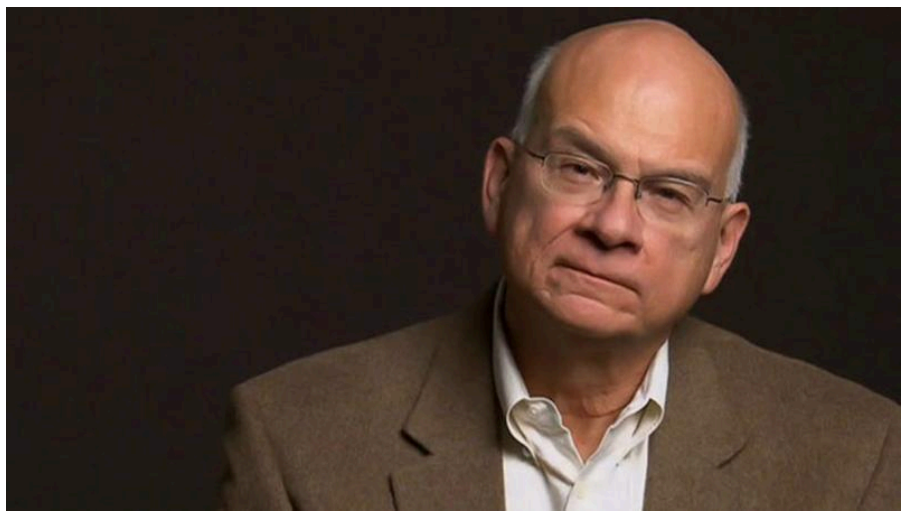

Last month I presented this work to the Dabar Conference, a gathering of over 70 conservative scholars to study creation theology. This is what one historian, Clinton Ohlers, explained about this work:

What struck me as extremely important in Dr. Swamidass' analysis both last summer and again at Dabar this year was primarily two things...that seem to recur in the history of science and Christianity. The first is that a scientific discovery and its seeming implications are treated as settled science and demands are made for a radical 
departure from recognizable Christian theology. The second is the appearance of a more sober corrective that recognizes the legitimacy of the discovery, but clarifies the real implications and in so doing provides breathing room for real theological reflection, development, and genuine intellectual progress. This second pattern is what I see Dr. Swamidass' analysis contributing, what made it so significant then, and why it generated such energy and engagement at the Dabar conference.

The scholars at Dabar and The Creation Project care. My discussion group at Dabar included William Lane Craig, Jack Collins (PCA), Richard Averbeck (TEDS), Ken Keathley (SEBTS), and Robert Shultzs (TEDS). They all care. William Lane Craig, seeing new scientific clarity arise, entered into a two year project to study the historical Adam. His involvement here is exciting, providing a rare model of wise leadership wrestling in public about important questions that face the work. He cares. Ken Keathley encourages deeper study on a Genealogical Adam too. He also cares.

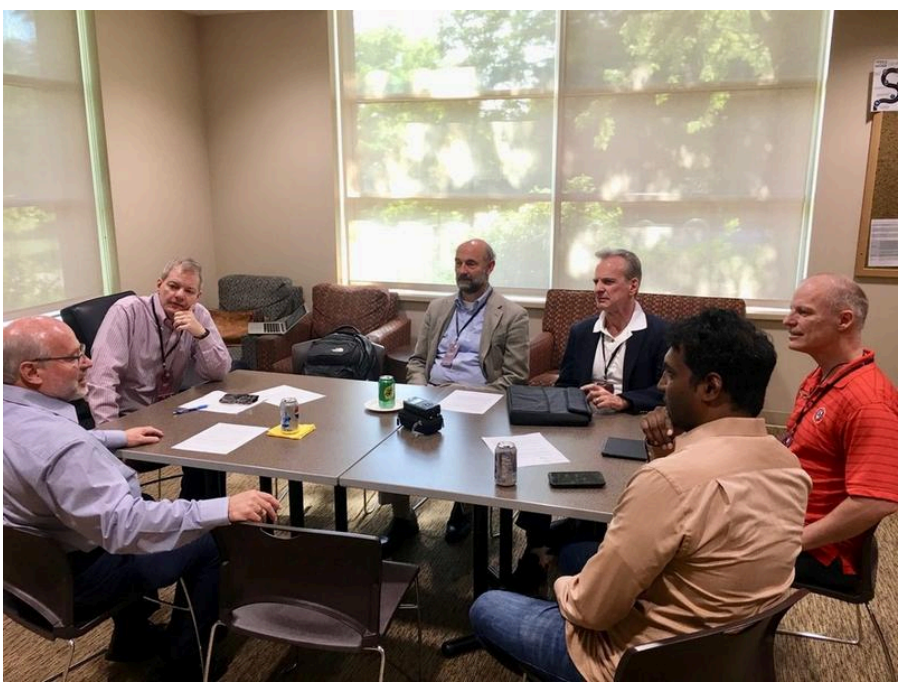

\section{We All Should Care...}

It is not merely important for just those who care about a historical Adam. These questions bring us to the grand questions of origins: what does it mean to be human? Wondering in this question, I've been personally changed by my experiences this last year. In the most visible way, I am not longer with BioLogos. This is just one of the many ways my life was turned upside down, bringing me back to central questions.

What is ancestry? This January my father died, and that week I spoke at three Veritas Forums. It is humanizing to grieve in public. Humans are the only creatures that seek out their birth parents if they are adopted. We are the only creatures that can contemplate the long chain of ancestry from which we come. It tells us who we are and where we came from. Ancestry is our inheritance, and we find in it both joy and grief. The meaning of "ancestry" is one of the humanizing questions of origins arising now.
What is our inheritance? This year is the 50th anniversary of Martin Luther King's assassination. It is worth remembering that we inherit a broken fallen world, a world with real injustice. Just as some of the most important advances were taking place last year, my world turned upside down. I wrote in the ASA magazine.

In the shadow of Ferguson, I gathered this Fall with seminary professors and friends in Saint Louis. On a monthly basis, we met to discuss Dr. King's sermons and writings at Concordia Seminary. Some of our first readings were The Ethical Demand for Integration and Paul's Letter to the American Christian.Just two weeks after our first meeting, the Stockley verdict was announced, and a police officer was acquitted. The streets outside my home exploded in protest. I walked onto Delmar Boulevard at night, unprepared for what I saw. My scientific training was worthless for the moment. On the street, watching the clash between non-violent protesters and the police, the scientist finds his limits. Science can neither name nor end injustice. I was reminded why Dr. King chose to study theology.

To receive our inheritance is to grieve the depths of how far we have fallen from the Kingdom of the God. It is to mourn for the things that can not be returned. The grand questions of origins bring us here, to contemplate the truth of our current moment. We should all care. To think about Grand Questions, after all, is part of what it means to be human.

What is community? I also wonder about a reordering of the current origins debate. Instead of advocating answers, what if we could lay down arms and approach the grand questions together? What if we could find community by walking out into the no-man's land of conflict, to risk friendship with those from the other side? I see new order. It might begin to emerge...

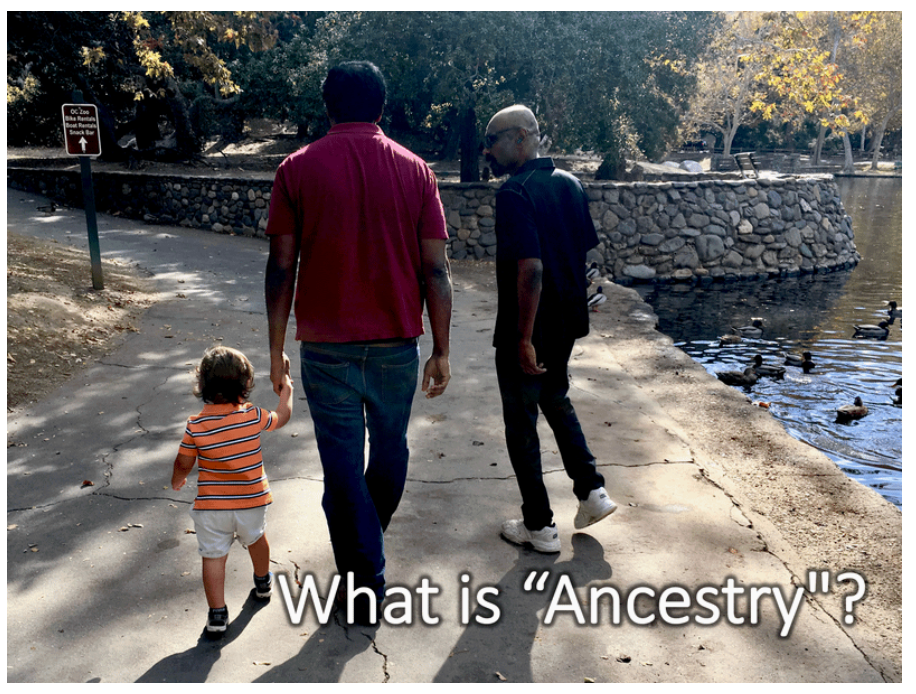

\section{The Conversation Continues...}

Join us on the forums this week to discuss the workshop with Greg Cootsona. Perhaps some of the other panelists might show up too. 


\section{References}

https://peacefulscience.org/articles/reworking-adam/ https://discourse.peacefulscience.org/t/_/849/9

https://discourse.peacefulscience.org/t/_/597

https://discourse.peacefulscience.org/t/_/591/3

https://discourse.peacefulscience.org/t/_/987

https://discourse.peacefulscience.org/t/_/988

https://discourse.peacefulscience.org/t/_/986

https://peacefulscience.org/articles/genealogical-rapprochement/

https://peacefulscience.org/books/adam-genome/

https://discourse.peacefulscience.org/t/_/61

https://discourse.peacefulscience.org/t/_/378 https://peacefulscience.org/articles/assess-rtb-model/ https://peacefulscience.org/articles/reviewing-adam-and-the-genome/ https://peacefulscience.org/articles/genealogical-science/ https://peacefulscience.org/articles/defense-tim-keller/ https://discourse.peacefulscience.org/t/_/568/40 https://discourse.peacefulscience.org/t/_/658/1 https://discourse.peacefulscience.org/t/_/568 https://discourse.peacefulscience.org/t/_/77

https://godandnature.asa3.org/essay-grieve-the-segregation-ofscience-by-s-joshua-swamidass.html 